\title{
The experiences of patients with rheumatoid arthritis admitted to hospital focused on 5 interrelated themes
}

Edwards J, Mulherin D, Ryan S, et al. The experience of patients with rheumatoid arthritis admitted to hospital. Arthritis Care Res $2001 \mathrm{Feb} ; 45: 1-7$.

\section{QUESTION: How do women with rheumatoid arthritis (RA) experience inpatient hospital care?}

Design

Phenomenology.

\section{Setting}

1 hospital in Staffordshire and 1 hospital in West Midlands, UK.

\section{Participants}

9 women (mean age 54 y) who had RA for $\geqslant 3$ years (range 3-42 y, mean 13.8 y) and had received inpatient treatment for $\geqslant 5$ days within the previous 2 years. 5 patients were admitted to a dedicated rheumatology ward, and 4 were admitted to an internal medicine ward.

\section{Methods}

Patients participated in unstructured individual interviews of about 1 hour. Interviews were tape recorded, transcribed verbatim, and analysed using Colaizzi's method. The analysis was discussed with 3 participants to confirm that it was a reasonable account of their experiences.

\section{Main findings}

5 interrelated themes were identified. The first theme involved the uncertainty that women experienced before and during their first admission with RA. Feelings of uncertainty ranged from nervousness to actual fear. Fear of the unknown was prominent as patients expected that "something would be done to them", and were concerned about what that "something" would be. Fears about intra-articular injections caused substantial stress. The second theme referred to patients' evolution from novice to experienced patients. With subsequent admissions, the fear and uncertainty of the first admission evolved to a sense of belonging and comfort. Patients came to see hospital admission as a learning experience, with their increased knowledge helping them to cope with future admissions. They became experts and mentors for novice RA patients. The third theme focused on the effects of other patients. Patients expressed a strong sense of comradeship, and the process of sharing experiences with others was described as invaluable; however, 2 of the younger patients (ages 24 and 26 y) expressed that contact with older patients was a negative experience. Although acknowledging that meeting peers with RA who could act as role models was helpful, they were distressed at witnessing the deformed joints of older patients, thinking that their own disease would progress in similar ways. They also spoke of the negative social effects, complaining that they were bored and had nothing in common with older patients. The fourth theme related to the knowledge and experience of the staff. All patients were confident in the abilities of ward staff.
The fifth theme, loss of privacy, was unique to the 2 younger patients who felt that their emotional and personal needs were rarely considered. The negative effect of RA on body image was intensified by admission to hospital. Experiences such as relying on nurses for intimate personal needs and undressing in front of staff on consultant rounds were particularly distressing.

\section{Conclusion}

The experiences of patients with rheumatoid arthritis who were admitted to hospital focused on 5 themes: uncertainty during first admission, becoming an experienced patient, the positive and negative effects of other patients, the experience and knowledge of staff, and the loss of privacy.
Source of funding: no external funding.

For correspondence: Ms J Edwards, Department of Rheumatology, Cannock Chase Hospital, Cannock, Staffordshire, UK.

sharon.murphy@ msgh-tr.wmids.nhs.uk

\section{COMMENTARY}

RA is a chronic, usually progressive, and severe illness that affects women about 2.5 times more frequently than men. About $1 \%$ of adults worldwide have RA. ${ }^{1}$ These patients may require several hospital admissions for their illness.

Although not specified, the assumption is that patients in the study by Edwards et al were admitted for treatment of their RA. They reported that hospital treatment for RA often involved painful procedures and placed the patient at a loss of control. Patients with RA who are admitted for other diagnoses and treatments may have different experiences. Neither the stage ${ }^{2}$ nor functional status ${ }^{3}$ of RA was reported. This is important because RA can vary from stage I (early) to stage IV (terminal). The functional status can vary from class I (completely able to perform activities of daily living [ADL]) to class IV (limited ability to perform ADL). Patients with different stages and functional status levels could be expected to report different experiences when admitted to hospital, which may account for some of the results.

The findings of Edwards et al indicate that nurses caring for patients with RA should consider patients' previous experiences when planning care. Experienced patients report that they need different support than first time patients. Also, patients in the earlier stages of illness may be distressed by seeing patients with later stages of illness, particularly when they know that their illness will likely progress as well. Patients may also be struggling with poor self esteem related to a negative body image. Perhaps the most important clinical recommendation is to design a unique plan of care for each patient based on his or her specific needs or desires concerning information, relationships with other patients, body image, and privacy. These informants clearly indicated that they did not all want to be treated alike.

\section{Michael Carter, RN, DNSc University Distinguished Professor College of Nursing The University of Tennessee Health Science Center Memphis, Tennessee, USA}

1 Carter M. Rheumatoid arthritis. In: Price SA, Wilson LM, editors. Pathophysiology: clinical concepts of disease processes. Fifth edition. St Louis: Mosby, 1997.

2 Steinbrocker $\mathrm{O}$, Traeger $\mathrm{CH}$, Batterman RC. Therapeutic criteria in rheumatoid arthritis. JAMA 1949;140:659-62.

3 Hochberg MC, Chang RW, Dwosh I, et al. The American College of Rheumatology 1991 revised criteria for the classification of global functional status in rheumatoid arthritis Arthritis Rheum 1992;35:498-502. 